\title{
El Informe Linowitz y las relaciones Estados Unidos - América
}

\author{
EL INFORME Y SU ENFOQUE
}

\section{Principales caractoristicas}

El segundo Informe Linowitz es un breve documento que fue divulgado con fecha de 20 de diciembre de 1976, por la "Comisión sobre las Relaciones entre Estados Unidos y América Latina", presidida por el señor Sol M. Linowitz, conteniendo comentarios sobre su tema y presentando un conjunto de 28 proposiciones específicas.

La Comisión Linowitz, constituida por decisión presidencial, ya habia sometido, en octubre de 1974, un primero y más amplio informe, bajo el título de "The Americas in a Changing World". Dicho estudio fue publicado en forma de libro, con algunos agregados, por Quadrangle Press, en 1975. La linea central del primer informe consistía en recomendar la terminación de la llamada "relación especial" de los Estados Unidos con América Latina. Se reconocia que tal relación era un eufemismo para el ejercicio de una tutela paternalista de los Estados Unidos sobre América Latina, ya no compatible con la realidad de las cosas. En las condiciones actuales, habia que establecer relaciones más abiertas y mutuamente ventajosas.

El segundo Informe parte de las conclusiones del anterior y agrega algunas nuevas consideraciones y propuestas. En sus líneas generaies, el Informe busca situarse en la posición más liberal posible, dentro de una perspectiva en que se supone que, en lo fundamental $-y$ tomadas en cuenta las recomendaciones del primero--, las relaciones Estados Unidos-América Latina son correctas y mutuamente favorables, exigiendo, sin embargo, algunas rectificaciones y perfeccionamientos.

Las rectificaciones propuestas se refieren a Panamá y a Cuba. E1 nuevo Informe recomienda que se firme un nuevo Tratado con $\mathrm{Pa}$ namá, que asegure la soberania de ese pais sobre el canal, asi como la gradual transferencia del control operacional de éste, garantizándose a los Estados Unidos el pleno derecho de uso sobre el mismo. En 
Io que respecta a Cuba, recomienda el restablecimiento de relaciones normales, en los planos diplomático y económico.

Ios perfeccionamientos propuestos por el nuevo Informe se refieren, sobre todo, al área económica. En síntesis, proponen un substancial aumento de los fondos disponibles para proyectos de desarrollo, por intermedio del Banco Mundial y del BID. Y recomiendan un régimen comercial cuya pauta sea la libertad de comercio, con supresión de las trabas de toda la suerte que limitan el acceso al mercado norteamericano de América Latina. Asimismo, preconizan una política de estabilización de los precios de las materias primas.

El Informe también contiene consideraciones y proposiciones de tipo político y social. Proclama sus militancia en lo que se refiere a la defensa de los derechos humanos, cuyo cumplimiento actualmente no está bien asegurado en América Latina. Y recomienda una política de limitación cle armamentos, con estricta prohibición de las armas nucleares $y$ una activa supervisión internacional para evitar la proliferación atómica.

\section{Implicaciones del Informe}

EI nuevo Informe Linowitz es una honesta y objetiva contribución para mejorar las relaciones entre los Estados Unidos y América Latina a partir del presupuesto de que las bases sobre las que se apoyan actualmente tales relaciones son correctus y bilateralmente ventajosas. Tal presunción, en lo fundamental, es compartida de un modr generni por los gobiernos latinoamericanos y por las fuerzas clirigentes de la región, con la obvia excepción de Cuba y con divergencias de parte de países como Venezuela y México.

Es indispensable, asi, para un análisis de las relaciones entre los Estados Unidos y América Latina, diferenciar, de partida, dos pers. pectivas distintas. La perspectiva que considera el statu quo como básicamente correcto, o por lo menos aceptable - que es la de Linowitz- $y$ que hace recomendaciones destinadas al perfeccionamiento marginal del tipo de relacionamiento vigente. $Y$ la otra perspectiva, que considera que el problema esencial no consiste en mejorar el actual patrón de relaciones, sino en cambiar su estructura.

La segunda perspectiva, a su vez, se presenta claramente, en dos variantes. Una, que llamaré "reformista", propone un tipo aiternativo de relaciones entre Estados Unidos y América Latina, que se caracteriza porque busca maximizar la autionomía cle la región y de sus países respecto de Ios Estados Unidos. Esa autonomía, en último análisis, es. compatible con los intereses fundamentales de los Estados Unidos 
y șe inserta en el cuadro de un capitalismo mundial modificaclo. Presupone, en los paises latinoamericanos, un profundo cambio económico, social y político, encaminado a la substitución clel capitalismo periférico por un capitalismo nacional, fuertemente socializado y con predominante actuación del Estado. Tales cambios son entendidos como realizables, en principio (no necesariamente), por una vía reformista. $\mathrm{Y}$, por eso mismo, implican. también una solución reformista para la alteración del actual tipo de relaciones de América Latina con los Estados Unidos, con ristas a la creciente autonomia de la región.

La seguncla variante, que llamaré "revolucionaria", considera imposible cambiar el tipo vigente de relaciones entre América Latina y los Estados Unidos sin un previo cambio revolucionario de las condiciones politicas, económicas y sociales en América Latina. Asimismo, aunque la literatura sobre el tema sea manifiestamente escasa, habría más bien que presuponer que los partidarios de la solución revolucionaria consicleran igualmente necesaria -como condición previa o como conclición subsiguiente-- un cambio igualmente importante de las relaciones de fuerza entre los Estados Unidos y la Unión Soviética, con suficiente incremento de la influencia de ésta para neutralizar intervenciones norteamericanas en América Latina.

\section{Perspecliva del Informe}

A partir de su perspectiva "situacionista", el segunclo Informe Linowitz toma una posición bastante lúcicla respecto de las relaciones entre Estados Unidos y América Latina. La crítica al paternalismo, contenicla en el primer Informe $y^{r}$ asumida como base del segundo, pone de inanifiesto, la medida en que los Estados Unidos todavía no han comprendido bien que su predominio en América Latina no depende del ejercicio de la coerción sino de la activa voluntad de dependencia por parte de las élites latinoamericanas.

Extrapolando, inconscientemente, sus propios intereses y valores al cuaclro latinoamericano, el norteamericano tiende a creer que su hegemonía $\in s$ producto de formas eficaces, aunque ocultas, de la violencia, como en una tierra ocupada. Cree que, en último análisis, son los "marines" y las flotas $\rightarrow y$ las condiciones internacionales que permitan su empleo- los que garantizan el control de América Latina por los Estados Unidos. Y no se enteran de que las cabezas de puente de los "marines" y de las flotas son las élites locales.

Sol Linowitz, aunque sin este grado de realismo, se dio cuentra clardmente de que las bases del poder americano en América Latina son las élites locales y: su creciente cooptación por parte del capitalismo 
mundial, como miembros periféricos del mismo. Se trata, por lo tanto, de maximizar la reciprocidad de intereses entre el capitalismo central y el periférico. Abrir el mercado norteamericano a los productos latinoamericanos, sacrificando eventualmente los sectores de baja tecnología de los Estados Unidos a ia competencia de los productores latinoamericanos, en su calidad de rama sucursal del capitalismo central.

Se trata, igualmente, de maximizar los flujos de capital norteamericano, directos o por vía de los bancos de desarrollo, que alimentan la dependencia latinoamericana. Se trata asímismo, de eliminar todos los vestigios residuales de formas semicoloniales de predominio y dar a los gobiernos y a las élites latinoamericanas irrestrictos derechos de miembros (minoritarios) del club capitalista. La esencia de las formas actuales de la dominación del capitalismo central es la cooptación del capitalismo periférico.

El precio que hay que pagar por esa incorporación de América Latina por intermedio de la cooptación de sus élites es, del lado norteomericano, extremadamente moderado. Hay que encaminar hacia otras actividades, a un costo social perfectamente tolerable, los capitales y la mano de obra que insistieron en. permanecer en actividades intensivas de trabajo, como es el caso típico de la inclustria del calzado, xservándose tales actividades para el capitalismo sucursal.

El verdadero precio de esa cooptación se paga en América Latina. Lo pagan las masas marginadas. La inspiración de las economías latinoamericanas en un modelo de capitalismo periférico, aunque se le reservasen en el mercado internacional los sectores mús intensivos de trabajo - io que todavía no ocurre- se caracteriza por una creciente falta de relación entre el incremento del empleo y el crecimientio demográfico. Solo países como Argentina, de muy bajo crecimiento demográfico y alta productividad agrícola, tienen capacidad de ajustar toda su población al modelo periférico. Los demás están obligados a sostener cuotas crecientes de marginalidad. Para hacerlo, necesitan de formas cada vez más represivas y antidemocráticas de gobierno.

Este aspecto, evidentemente, no fue comprendido por Sol Linowitz. Solamente esa falta de comprensión de la intima conexión existente entre el capitalismo periférico, la marginalidad y las formas antidemocráticas de represión político-social, pueden explicar como, sin apelar al humor negro, el Informe Linowitz sea, al mismo tiempo, un lucido esfuerzo para optimizar las relaciones entre el capitalismo central y el periférico, y un manifiesto a favor de la defensa de los derechos humanos en el mundo subdesarrollado. 


\section{Breve recapitulacion historica}

El entendimiento del actual tipo de relaciones entre América Latina y los Estados Unidos y de las posibilidades de cambio de dicho tipo exige una brevisima recapitulación histórica de las relaciones entre las élites latinoamericanas y el capitalismo central. No es menester: para ese efecto, considerar las formas iniciales de inserción de las economías latinoamericanas en el mercado mundial, a partir del siglo XVI. Bastá analizar las características centrales de tales relaciones desde el siglo XIX.

Habia dos mundos distintos, aunque complementarios y por eso reciprocamente cooperativos. Sin embargo, a pesar de la existencia de una básica comunidad de estilo (aristocrático-burgués) y de cultura (de base franco-inglesa), cada lado tenia su propia vida e intereses internos. Eso imprime un sentido de considerable autonomía interna (aunque afectada por el proselitismo cultural) a la vida nacional de los países latinoamericanos. Conservadores, en el siglo XIX, liberales, desde fines del siglo hasta la crisis de 1930, las élites político-económicas de América Latina persiguen la idea de construir naciones independientes, que aspiran a tornarse tan civilizadas como las europeas pero con sus propias personalidades.

Las crisis de 1930, como es sabido, produjeron irremeriable discripción en el tipo de relaciones de América Latina con los países centrales - ya entonces bajo el predominio de Estados Unidos. Al disponer más de condiciones para adquirir todo lo que necesitaban con el producto de sus exportaciones primarias, los paises latinoamericanos fueron conducidos a un proceso de industrialización por substitución de importaciones. Primero, de forma espontánea y no deliberada, hasta la segunda guerra mundial. En seguida, de forma consciente y programada, en el curso de las décadas de 1950 y 1960 . Son las décadas de las democracias populistas, de Vargas, y Perón, de Kubitcheck, y Frondizi. Son también las décadas en que se define conscientemente una burguesía nacional. Sin embargo de sus vínculos con el capitalismo internacional, ya fuertemente dominado por las grandes empresas monopolistas, el empresariado latinoamericano juega una carta propia.

De formas variadas, de país a país y tambièn en el curso del tiempo, se configura, sin embargo, en lo fundamental, un cierto tipo de aso- 
ciación entre el empresario nacional, el Estado, y los sectores organizados de la clase obrera. Aunque frecuentemente los empresarios latinoamericanos sean imigrantes europeos, o de reciente procedencia europea, sus capitales son básicamente de origen local, con decisivos aportes del sector público.

La controversia que se generó más tarde, cuando ya se había cambiado la tónica del sistema, sobre la medida en que los valores y objetivos de las burguesías nacionales latinoamericanas tenían efectivamente un carácter nacional, se basó en datos y en actitudes de una segunda generación de empresarios, que no reflejaban ya los de la época autonomista de la fase de implantación del desarrollo industrial.

Durante esa segunda fase de las relaciones de la economía latinoamericana con la mundial, marcada por el proceso y el propósito de autonomización industrial, el relacionamiento de las élites de América Latina con los países centrales, especialmente Ios Estados Unidos, expresa una posición distinta. Como en la fase precedente, se mantiene la diferenciación de los dos lados. Subsisten formas de complementaridad. La industrialización incipiente de América Latina exigia una parte todavía predominante de equipos de procedencia externa. Ade'más, creaba nuevas demandas de financiación.

Pero, por otra parte, los conflictos no eran mảs de carácter meramente adjetivo, ni se podian componer por vía simplemente automática. Eran conflictos de "policy", que derivaban de oposiciones de intereses $y$, en último término, de incipientes conflictos de poder entre un sistema central, que perclia elementos de hegemonía y un sistema periférico que se organizaba con sentido autónomo, o sea, como un centro alternativo, aunque de más bajo nivel. Por eso mismo esa fase clará nacimiento a las llamadas políticas externas inclepen. dientes, de que serán ejemplos los intentos iniciales de Perón y Vargas, y' más tarde, de Janio Quadros y de Frei.

La crisis del populismo, en la década de 1960, conducirá al colapso político a los gobiernos populares en América Latina. No sería posible, en esta brevisima recapitulación histórica, discutir, aun sumariamente, las causas de la crisis del populismo, que afectaron tan decisivamente el destino de los paises latinoamericanos. Me limitaré a una única y fundamental observación. Se refiere al hecho de que, entre los varios factores de la crisis del populismo, se destaca el agotamiento, en las concliciones de entonces, del modelo que venía configurando el proceso de desarrollo industrial de América Latina.

En síntesis, el desarrollo populista, aunque orientado y estimulado por el Estado, dependía de la iniciativa privada y de la clemanda doméstica. Razones diversas, que no sería posible aquí exponer, han 
producido, antes que se ultimase el proceso de industrialización, una insuficiencia de la demanda interna, sin posibilidades de compensarla por via de exportaciones. El primer resultado de esa crisis ha sido el estancamiento, en condiciones de creciente inflación, de las economías Iatinoamericanas, en la década de 1960. Con esto se desencadenan contradicciones sociales internas que conducen a la crisis del populismo y a su colapso final político.

La fase que se sucede y en que nos encontramos, a partir de la segunda mitad de la década de 1960, conducirá a una rápida transformación del proceso productivo de los países latinoamericanos de mayor desarrollo industrial. La característica básica de esa transformación será la intemacionalización de la industria latinoamericana. $\mathrm{Ni}$ el Estado, ni el empresario nacional, en el periodo populista, tuvieron capacidad de ultimar el proceso de la industrialización, incluso en los paises de mayor desarrollo industrial como Argentina, Brasil y México. En seguida a la crisis del populismo (que en México tendrá la forma más atenuada de la crisis del gobierno de López Mateos y su sucesión "internacionalista" por Díaz Ordaz) serán las empresas multinacionales que retomarán el proceso de desarrollo. Las multinacionales comprarán usinas y fábricas de la antigua burguesía nacional y las expandirán con nuevos recursos y técnicas, así como se instalarản nuevas sucursales.

La demanda doméstica no crecerá de acuerdo con esas nuevas inversiones. Pero se abren subitamente las puertas, hasta entonces cerradas, de los mercados internacionales. De México a Chile, América Latina se convierte, nuevamente, en gran exportadora para. el mercado mundial. Ahora, entretanto, no serán simplemente productos primarios, como en la primera fuse. Serán también manufacturas, principalmente aquellas de trabajo más intensivo, las que se encaminarán para ocupar, como precedentemente ya se mencionó, significativas parcelas del mercado mundial, incluso del norteamericano.

\section{El capilalismo ferifúrico}

La tercera y actual fase de relacionamiento de la economía latinoamericana con la mundial se caracteriza por una integración, en un solo sistema, del capitalismo mundial y del capitalismo latinoamericano. En tal integración se diferencian centro y periferia. Se trata, entretanto, de una diferenciación distinta de la que existia en la primera fase, entre el centro manufacturero y la periferia primarioexportadora. No hay más "dos lados". Hay ariba y abajo, en un lado único. El otro lado, tiene sentido socio-político. Es, extemamente; la 
Unión Soriética e, internamentc, el frente subversivo. El otro lado es el enemigo común.

El sistema productivo caracteristico del capitalismo periférico se basa en una estrecha asociación entre las multinacionales, el Estado y el empresario nacional. No se busca más la autonomía nacional, como tal, aunque subsistan mitos y ritos del nacionalismo clásico. En parte, por falta de coherencia interna de la nueva ideología dominante: la de la seguridad supuestamente "nacional". En parte por cleliberada manipulación de ese otro opio del pueblo que es el sentimiento nacional. En lugar de autonomía nacional, como tal, se buscan formas internas y externas de integración de mercados.

El Estado se convierte en agente central del proceso productivo, aunque ideológicamente subscribe la tesis de la iniciativa privada. Actúa, por un lado, como un promotor y garantizador del mercado doméstico, que pone a disposición de los empresarios (nacionales y multinacionales), garantizando varias formas de asistencia financiera $y$ fiscal, en cambio del cumplimiento de ciertas metas de producción, de exportación y de rendimiento. Por otro lado, actúa como un negociadior de facilidades externas: capitales, tecnología y mercados para la exportación.

La empresa multinacional resulta, objetivamente, ser el socio principal del Estado, porque está mucho mejor preparada que la nacional para ese tipo de transación. Para conquistar las facilidades dadas por el Estado dispone de muchas mejores condiciones de capital de tecnología y, sobre todo, de acceso a los mercados externos.

El empresario nacional, en tal coyuntura, se encamina básicamente hacia dos opciones. Una consiste en convertirse en socio minoritario de la gran. empresa multinacional. Tiende a ofrecer a las multinacionales $y$, frecuentemente, una buena base previa de instalaciones $y$ mercado. Tiene que recibir la garantía de un constante flujo de capitales y tecnologia y el acceso a los mercados externo, lo que, a su vez, asegura el estable y continuo desarrollo de la empresa.

La segunda opción del empresario nacional es la de refugiarse en los sectores de altos insumos de trabajo, que interesan poco a las multinacionales. En, este caso tambićn se torna un socio menor del capitalismo internacional. Ya no de forma directa, pero indirectamente, por ser el participante secundario del sistema.

Para una sociedad dominada por ese modelo de producción y por los intereses en él predominantes, el tipo de relación internacional que le conviene, especialmente con el pais hegemónico del sistema capitalista, es, lo fundamental, lo que recomienda el Informe Linowicz. Es por tal razón, como anteriormente se observó, que el Inforre Linowitz, dentro de su perspectiva y a partir de sus premisas, con- 
tituye un lúcido $y$ honesto intento de optimizar las relaciones entre centro y periferia.

\section{Posibilidades del reformismo}

En que medida, cladas las nuevas condiciones que se formaron en América Latina, a causa y a continuación de la crisis del populismo, se podría concebir un cambio en el tipo interno de producción y, correlativamente, de las relaciones con los Estados Unidos y los paises centrales?

Como se subrayó al principio de este estudio, una perspectiva que se oponga al actual status quo en América Latinal y, por lo tanto al actual tipo de relaciones con los países centrales, se divide, claramente, en dos variantes, la reformista $y^{\prime}$ la revolucionaria. Vamos a considerar ahora, muy brevemente, la alternativa reformista.

El populismo era reformista, doméstica e internacionalmente, porque intentaba, aunque cle forma vaga y mal articulada, la intención, en lo interno, de incorporar las masas al proceso nacional y, externamente, de maximizar la autonomía nacional y regional frente a los paises centrales. Tal reformismo implicaba, por un lado, una significativa redistribución interna $y^{\prime}$ externa de oportunidades, ingreso' $y$ poder. Por otro lado, una básica compatibilidad entre ese proyecto y los requisitos funclamentales, internos y externos, del capitalismo.

El primero aspecto mencionado no demanda excesiva elaboración. Es cierto que el populismo era retórico y bastante inconsistente y jugaba más con promesas del futuro que con realizaciones del presente. Sin embargo, producía algunos resultados concretos y ejercía, indudablemente, un importante rol redistributivo, tanto internamente como internacionalmente.

El segundo aspecto del populismo no es menos verdadero, a pesar del lenguaje frecuentemente radical de éste. Es que, en lo fundamental, el populismo conducia a un modo de producción fundado en la iniciativa privada, aunque marcado por fuertes compromisos sociales $y$ decisiva interferencia del Estado. En el marco de un nuevo tipo de responsabiliclad social y nacional, el populismo implicaba la existencia cle empresas privaclas, coexistiendo con empresas públicas. Aquellas y estas, por otro lado, tendrían toda suerte de intercambios cont las empresas de los países centrales. Lo que se buscaba imponer a estos, en principio, ni era la supresión de la empresa privada, en las áreas de la periferia, ni la ábolición, en plazo previsible, de la superioridad relativa cle los países centrales y sus empresas. Se impon- 
dría apenas una mayor disciplina social y nacional $y$, sobre todo, una tendencia a largo plazo igualizante.

La posibilidad de un retorno, en América Latina, a una situación interna y a una política externa de tipo reformista implica un cambio correspondiente en su estructuración económica, social y política. Implica, en cierta forma, un nepopulismo. Las caracteristicas básicas de ese cambio son: 1) recuperación, por las masas, de su capacidad de presión social, económica y política; 2) restablecimiento de una alianza nacional entre las fuerzas sindicales, la burguesía nacional y las clases medias progresistas; 3) recuperación, por el Estado, cle su rol de promotor de la autonomia nacional y regional.

La ocurrencia de cambios sociales de ese tipo es un fenómeno complejo, que depende de muchos factores, reales e ideales. Entre tales factores se destacan, de un lado, el grado de insatisfacción generado, entre las diversas fuerzas sociales, por el modelo vigente. De orro lado, la medida en que los líderes que propongan el modelo alternativo tengan capacidad de atraer para ello expectativas suficientes para cambiar el status quo.

Un nuevo jopulismo, en América Latina, jamás podría ser una reiteración del anterior. Esta tesis, que exprime de un modo general, un consenso que resulta de razones de diversos orígenes, no podría ahora ser apropiadamente aclarada. Es suficiente mencionar que las burguesias latinoamericanas sólo aceptarán volver a jugar la carta nacional si, aunque dentro de una disciplina social que podría tornarse muy seria, tengan seguridad cle contar con el total respaldo del Estado y por lo tanto, en muchos aspectos, de controlarlo. Ese respaldo implica para esas fuerzas, aclemás cle otras, condiciones que les garantizen: 1) la persistencia de sectores claves de la economía bajo gestión privada; 2) el apropiado flujo cle capitales, incluso foráneos, para la expansión de las empresas; 3) apropiado acceso a las mejores fuentes de tecnología; 4) apropiado acceso a los mercados domésti$\cos$, regionales e internacionales.

La discusión de la medicla en que, en las presentes condiciones de América Latina y del mundo, se pueda prever, por un lado, al agotamiento de las posibiliclades clel actual moclelo del capitalismo periférico $\mathrm{y}$, por otro lado, el advenimiento de concliciones favorables a un modelo reformista, como el precelentemente delineatlo, es algo que sobrepasa la restringida longitud de este estudio.

Sobre el asunto me limitaré a dos observaciones. La primera se refiere al hecho de que el capitalismo periférico, a pesar de las impresionantes fuerzas que, interna $y^{\prime}$ extemamente, todavía le dan respaldo, manifiesta evidentes señales de agotamiento en América Latina. Argentina, como ya se mencionó, es quizás el pais en que las 
condiciones estructurales serían más. favorables a ese modelo. Pero es también el país más politizado en el sentido nacional y social de toda la región. Y el que dispone de una clase obrera más bien organizada y pujante y de una clase media más coincidentemente nacionalista.

Por lo contrario, el Brasil, pais cle socicdad menos estructurada $y$. de masas más inermes, es también! aquel adonde la más desinhibida y larga aplicación del modelo del capitalismo periférico terminó desembocando en una crisis generalizada del sistema en que los problemas de Ia inflación, del pleno empleo y' de las necesidades de rigorosas exportaciones, dictadas por la inmensa deuda externa, crean exigencias recíprocamente incompatibles, dentro del modelo.

La segunda observación, que es importante hacer, se refiere al hecho de que la experiencia de los fracasos del populismo, en la década de 1960 , parece haber contribuido para una sabia revisión estratégica y táctica. por parte de las fuerzas populares en América Latina, expurgándolas de muchas de las formas más infantiles del izquierdismo. ¿Se estarán dando condiciones para una nueva formulación del modelo reformista?

Sea cual sea la contestación a la pregunta precedente, conviene tomar en cuenta, además de la crisis socioeconómica que existe en la mayor parte de los paises latinoamericanos, el importante hecho da que en un pais tan bien dotado de recursos como Venezuela, hay manifiesta propensión, por parte de los dos particlos principales, a caminar en un sentido reformista. No se puede subestimar el impacto de Venezuela y de sus opciones domésticas e internacionales sobre Amćrica Latina cn general y, en particular, el bloque Anclino y. Brasil Tampoco se puede ignorar la medida en que México, a pesar de su gran dependencia económica de los Estados Unidos, fue profundamente novilizado, durante el gobierno de Echeverria, para, una solución reformista y autónoma.

LA PERSPECTIVA REVOLLCLIONARIA

¿Se puede hablar, en América Latina, de una perspectiva revolucionaria como algo dotado cle alguna unidad interna y alguna viabilidad política, en un plazo no excesivamente remoto?

La respuesta a esas dos preguntas se ha tornado extremadamente difícil. El proyecto revolucionario, en América Latina, ya estuvo en momentos históricos precedentes claramente identificado con de- 
terminados modelos. Asî es indudable que los partidos comunistas de filiación soviética, tuvieron, hasta la revolución cubana, el monopolio práctico de las expectativas revolucionarias en la región. Luego, las izquierdas revolucionarias, inspirándose en los ejemplos cubano y chino, desplazaron a los partidos comunistas hacia una especie de conservadorismo proletario y frenaron, por un tiempo, las esperanzas revolucionarias.

Muchas cosasł ocurrieron, en años más recientes, para desacreditar las izquierdas revolucionarias sin devolver prestigio a los partidos comunistas. Así, la lamentable actuación del ultraizquierdismo en Chile contribuyendo más que cualquier otro factor a la caída de Allende. La derrota de la guerrilla en Brasil, Uruguay y Argentina. $Y$ por otra parte, la creciente desmistificación del despotismo burocrático en la Unión Soviética y en Europa Oriental, contrastando con la persuasiva lucidez de la versión democrática del eurocomunismo, completaron el descrédito de las formas violentas de revolución.

¿Qué formas alternativas se están imponiendo en América Latina? La verdad es que la región no ha siclo capaz de formular, en términos cle sus necesidades y condiciones, el equivalente del eurocomunismo. Los viejos partidos comunistas, desgastados por la represión externa y por su propio burocratismo interno, no se están revelando capaces cle una respuesta a la altura de las nuevas condiciones. $Y$ los restos clel ultraizquierdismo, convertidos en sectas Kamikases, cumplen un trágico compromiso con sus convicciones personales, sin ninguna comunicación y conexión con sus respectivas sociedades.

A pesar de la ausencia de un proyecto revolucionario válido, la alternativa revolucionaria, en América Latina, no es algo que se pueda relegar al olvido. Hay, descle luego, dos aspectos que exigen seria atención. Uno se refiere al hecho de que la juventud latinoamericana, especialmente la universitaria, manifiesta en sus sectores más válidos una preferencia - nítida aunque todavía no exclusiva- por soluciones más radicales que las propuestas obtenibles no por vía de reformas. El capitalismo, como ya ha sido observado por muchos analistas, agotó su repertorio de valores antes de agotar su pragmática adaptabilidad a situaciones nuevas. En oposición a una sociedad furclada en. la explotación de las masas, en la desenfrenada competencia y en la ilimitada voracidad adquisitiva, la gente, particularmente la más joven, aspira a una sociedad más ecuánime, cooperativa, libre $y$ humana. Esto es un hecho y un dato cargado de inegables potencialidades históricas.

El segundo aspecto a subrayar se refiere a los efectos combinados del agotamiento de las posibiliclades sociales del capitalismo periférico, anteriormente mencionado, con la renuencia que vienen demos- 
trando poderosos sectores de las sociectades latinoamericanas a aceptar, oportunamente, soluciones reformistas. Sin discutir, ahora, la medida en que la farmacopea reformista contenga remedios suficientemente eficaces para sanár los males sociales de la región, es evidente que sus posibles efectos positivos dependen de la oportuna aclopción de las medidas convenientes.

La impávicla renuencia, por parte de las oligarquias conservadoras en América Latina, para aceptar cualquier forma de efectiva soberanía popular y de control legal sobre su arbitrio, son indicios de una peligrosa intención de perpetuación en la ilegitima detentación del poder. Ese tipo de conducta há sido, históricanente, el acumulador de presiones sociales que terminan con incontenibles explosiones revolucionarias. $Y$ es inútil recordar, ante la gigantesca y creciente marginalidad latinoamericana, lo que ya son las presiones sociales de la región $y^{t}$ lo que serán dentro de algunos años más $y$ hasta el fin del siglo.

Una eventual solución revolucionaria en América Latina, hasta el fin del siglo, produciria los más serios efectos disruptivos sobre el capitalismo mundial. Y cambiaría radicalmente el actual tipo de relaciones de la región con los países centrales, especialmente con los Estados Unidos. No está en los propósitos de este estudio especular sobre los posibles efectos de tal cambio. Me linitaré a observar que, a diferencia de la hipótesis de una alternativa reformista, que en último térnino es compatible con el sistema del capitalismo mundial -adaptado a las exigencias socio-nacionales de periferias autonomizada. In alternativa revolucionaria comportaria, necesariamente, relaciones de confrontación. Nacionalizaciones sin compensaciones y profundos cambios en la dirección y composición de los flujos del comercio internacional de la región son algunos de los efectos previsibles de ese cuadro de confrontación. 